\title{
Guinea: Joint Staff Assessment of the Poverty Reduction Strategy Paper
}

The attached Joint Staff Assessment (JSA) of the Poverty Reduction Strategy Paper Progress Report for Guinea, prepared by the staffs of both the World Bank and IMF, was submitted with the member country's Poverty Reduction Strategy Paper (PRSP) or Interim PRSP (IPRSP) to the Executive Boards of the two institutions. A JSA evaluates the strengths and weaknesses of a country's poverty reduction objectives and strategies, and considers whether the PRSP or IPRSP provides a sound basis for concessional assistance from the Bank and Fund, as well as for debt relief under the Enhanced Heavily Indebted Poor Countries (HIPC) Debt Initiative. The Boards then decide whether the poverty reduction strategy merits such support.

To assist the IMF in evaluating the publication policy, reader comments are invited and may be sent by e-mail to publicationpolicy@imf.org.

Copies of this report are available to the public from

International Monetary Fund • Publication Services

$70019^{\text {th }}$ Street, N.W. • Washington, D.C. 20431

Telephone: (202) 623-7430 • Telefax: (202) 623-7201

E-mail: publications@imf.org • Internet: http://www.imf.org

Price: $\$ 15.00$ a copy

\section{International Monetary Fund Washington, D.C.}





\author{
INTERNATIONAL MONETARY FUND AND \\ INTERNATIONAL DEVELOPMENT ASSOCIATION
}

\begin{abstract}
GUINEA
Joint Staff Assessment of the Poverty Reduction Strategy Paper Annual Progress Report
\end{abstract}

Prepared by the Staffs of the IMF and IDA

Approved by Siddharth Tiwari and Mark Plant (IMF) and

Callisto Madavo and Gobind T. Nankani (IDA)

November 23, 2004

\title{
I. OVERVIEW
}

1. The first annual progress report of Guinea's Poverty Reduction Strategy Paper (PRSP-PR) was formally submitted to the International Monetary Fund (IMF) and to the World Bank in April 2004. The report assesses progress made in implementing the PRSP during the calendar years 2002 and 2003, and lays out the measures the government is pursuing to achieve its policy objectives. The PRSP, which was approved by the Guinean government on January 2002, was endorsed by the Executive Boards of the Fund and the World Bank on July 2002. ${ }^{1}$

2. The staffs agree with the PRSP-PR conclusion that efforts have been made over the last two years to advance the poverty reduction strategy, even as the economic environment became more difficult and Guinea's program with the Fund went off-track. The report rightly states that in spite of the deterioration in the macroeconomic environment (due in part to exogenous factors), Guinea was still able to achieve many of its poverty and social targets, including those outlined for the HIPC completion point. The achievement of HIPC completion point targets and efforts to mobilize public resources for priority sectors under very tight budget constraints demonstrate the government's commitment to the PRSP. However, to ensure sustained poverty reduction, the staffs urge the country to make efforts to reduce the current

\footnotetext{
1 The completion of the progress report was delayed for various reasons. First, the authorities thought it important to broaden the consultative framework to the regional and local level before completing the report, and to deepen their analysis of the strategy. Second, delays were due to activities related to presidential elections held in December 2003, and substantial changes in government following the elections.
} 
macroeconomic imbalances, so that budgetary pressures do not affect the social sector as targets for cuts. More emphasis is required on the need to promote fiscal sustainability by containing defense spending, implement sound monetary policies that would result in the absorption of excess liquidity, adopt an exchange rate that reflects market conditions, pursue a strong structural reform agenda, and reduce vulnerabilities to external shocks.

\section{The staffs consider that the PRSP-PR provides a detailed assessment of} progress made in implementing the PRSP and outlines many of the lessons learned for future implementation. The report appropriately underscores the constraints that affected the implementation of the PRSP during the first two years. These include weak implementation capacity, notably at the local level, uncertainties in government revenues, pressures on spending due to regional security conditions, and weak domestic investment. In light of these constraints, the report adequately analyzes macroeconomic and sectoral performance under the PRSP and the medium-term macroeconomic framework has been appropriately revised. The PRSP-PR also provides a clear operational framework for the pursuit of a participatory approach to implementation of the strategy.

\section{However, the staffs note a number of weaknesses in the implementation of} the strategy and in the progress report: (i) the absence of a debt-sustainability outlook to support the strategy; (ii) the lack of a clear agenda of reforms in revenue collection and in the effectiveness of public spending, notably drawing on the recommendations of the public expenditure reviews (PER); (iii) insufficient analysis of the factors that would promote economic growth; and (iv) the lack of recent poverty data in the analysis, a problem that was already noted in the JSA of the PRSP (2002).

\section{Poverty Analysis, Monitoring, And Evaluation}

\section{The staffs recommend that the household survey be completed as soon as} possible and that the key determinants of poverty and their interdependency be identified. ${ }^{2}$ This would make it possible to track poverty impact over time. Comprehensive household survey data and their full exploitation are key to poverty analysis, and are only partially available in Guinea. The review of the PRSP called for an independent evaluation, with NGO participation, of the impact of poverty policies and programs on the poor and the most vulnerable, notably rural women and youth. So far, the public expenditure tracking survey (PETS), Core Welfare Indicators Questionnaire (CWIQ), and ad hoc surveys, while providing useful insights, have not provided sufficient evidence on changes in the status of the poor, notably because of delays in the completion of the household survey. The available results of the CWIQ suggest that while some progress has been made in terms of access to education, the levels of dissatisfaction with the quality of services remain high and are a cause for concern. Sixty four percent of students were dissatisfied with the quality of their education, while 53 percent of

\footnotetext{
${ }^{2}$ The JSA conducted in 2000 in relation with the I-PRSP made the same recommendation.
} 
households were dissatisfied with the quality of health care and 42 percent with access to health centers.

\section{The PRSP-PR would have been strengthened by providing more information} on the incidence of recent macroeconomic imbalances and adverse shocks on poverty. For instance, the impact of high inflation on the living conditions of the poor; the impact of insecurity and refugee inflows on the poor in the affected regions in particular (incursions in 2000 led to negative GDP growth for certain border regions that are still threatened). Poverty and social impact analyses (PSIA) would have been useful in this regard. The staffs further recommend that an analytical work program be drawn up, to be discussed with the development partners who may be willing to finance specific tasks.

7. The tracking of public expenditure in social sectors needs to be improved and progress reflected in the next PRSP-PR. The 2003 PETS for health and education, carried out under the PER, was an important step forward in terms of monitoring poverty reduction, although the results were not encouraging - only 16 percent of the non-salary recurrent budget reached targeted schools in the pilot regions and only 30 percent reached health centers. This could be refined by linking the tracking of school and health expenditures results to feedback from households sampled under the household survey and to those sampled by the recent anticorruption survey. This analysis would provide a unique opportunity for examining the impact of corruption on the provision of basic services to the poor.

\section{The Three Pillars of The PRSP}

\section{A. Sustaining Faster Economic Growth}

8. The staffs agree with the PRSP-PR that adverse, exogenous factors severely affected economic performance in 2003 , but stress that public policies also contributed to a worsening of the economic outlook. At 1.2 percent, economic growth in 2003 was substantially lower than projected in the PRSP (4.7 percent), as adverse external shocks unfolded - the heightened insecurity due to conflicts in neighboring countries, the deterioration of Guinea's terms-of-trade, and adverse climatic conditions. The staffs consider that the report downplays the disruptive role of inappropriate economic policies and sluggishness in the implementation of needed structural reforms, which notably explain the shortfalls in external assistance that affected macroeconomic performance in 2003. With the IMF program being off-track since December 2002 due to the lack of progress in policy implementation, potential external budgetary assistance is limited in the short-term. In the absence of external budgetary disbursements in 2003, an expansionary fiscal stance, due in part to excessive defense spending, coupled with an accommodating monetary policy, led to a large increase in CPI inflation from an average of 3.0 percent in 2002 to 12.9 percent in 2003 . These developments exemplify the need for sound macroeconomic policies to restore stability in the short-term and enhance growth prospects over the medium-term. 
9. Furthermore, the authorities need to more clearly identify the risks to implementation of the poverty reduction strategy, an issue raised by the 2002 JSA. In addition to exogenous shocks (bauxite prices; petroleum prices; climatic conditions), other key risks include: failure to implement sound economic policies, revenue shortfalls, difficulties in implementing the decentralization of expenditures, institutional weaknesses and overall lack of implementation capacity. Clearly identified risks would allow the authorities to plan measures ex-ante to limit their impact on poverty reduction.

10. The revised medium-term macroeconomic framework adequately adapts policy priorities to redress the degraded macroeconomic environment. The authorities recognize that the original PRSP targets for 2004-05 are clearly out of reach. They now envisage a consolidation period in 2004-05 followed by a resumption of a growth path of at least 5 percent per year beginning in 2006. During this consolidation period, real GDP growth is projected to average 3.2 percent per year compared with 5.9 percent in the original framework; inflation would still be in the double digits by end2005 instead of 3 percent; and fiscal revenues would be over 2.5 percentage points of GDP below the original target. However, the overall fiscal deficit (commitment basis, excluding grants) would reach around 4 percent of GDP under the new framework instead of an average of 7 percent of GDP under the original framework as a result of significantly lower spending and less grants. The new strategy is based on the pursuit of an emergency economic recovery program that started in April 2004, augmented with decisive progress in implementing structural reforms. On top of regaining macroeconomic stability, particular efforts will be devoted to contain non-productive spending and increase social outlays, so as to achieve the poverty reduction objectives.

11. In light of the vulnerability of the Guinean economy to external shocks, the staff reinforces the authorities' assessment of the need to diversify the structure of production and exports, and to improve the flexibility and competitiveness of the economy. In particular, the staffs:

- $\quad$ encourage the authorities to undertake a more comprehensive analysis of the key sectors driving economic growth and job creation, and to propose concrete actions to promote those sectors. In the agricultural sector and in rural development, the staffs recommend that such analysis be given high priority, possibly by including an inquiry into employment and wages in the rural development PETS which was originally scheduled for 2003;

- $\quad$ note that the competitiveness of the Guinean economy continues to be negatively affected by market distortions, poor infrastructure, a weak legal and judicial framework, and corruption. The PRSP-PR also recognizes that weak and sporadic 
supply of electricity and water has been a serious constraint on growth since 2000, however, it fails to quantify the impact; ${ }^{3}$

- $\quad$ recommend that trade-related issues and export diversification be given closer attention. In particular, specific measures to eliminate trade development constraints and to expand the capacity of sectors in which Guinea has a comparative advantage should be outlined. Recommendations from Guinea's Diagnostic Trade Integration Study can provide the basis for policy measures. Also, the next progress report could include a discussion of the potential impact of the Economic Partnership Agreement with the EU on Guinea's economy;

- $\quad$ suggest that continued implementation of government strategies in privatization and structural reforms should improve productivity over the medium term, and would need to be detailed further in the updated strategy; and

- $\quad$ encourage the government to consider undertaking a PSIA relative to the privatization of the public utilities. Such analysis could help to assess the appropriateness, timing, and sequencing of alternative reform designs based on their poverty and social impacts and would also help build country ownership of policies by eliciting a public debate on the trade-offs between policy choices.

\section{The PRSP-PR rightly emphasizes that weak revenue collection capacity is a constraint to the implementation of the poverty reduction strategy. Nonetheless, the} report would have benefited from a clear agenda of reforms in revenue collection. In addition, the staffs consider that greater attention could have been given to the effectiveness of public spending. The commitment of the government to social spending is laudable in a difficult budgetary environment. However, the staffs note that in light of an unsustainable fiscal deficit, the report could have enumerated detailed measures to curb spending in non-priority sectors, notably by setting ceilings for defense spending, and improve the effectiveness of spending in priority sectors, notably education, health and rural development. In that regard, the staffs recommend that a better balance be achieved between current and investment spending and that execution be strengthened. The staffs note that the public investment program (PIP) has not yet been fully integrated into the annual programming and budget process and that the estimation of recurrent costs is not given sufficient attention. A further concern is that there is no analysis of the

\footnotetext{
${ }^{3}$ As the PER notes, it is possible to identify specific costs to the private sector. For example, dependency on auto generation of electricity at the business level has increased substantially, after a significant decline following the first reform of the sector. Similarly, while reform of the public enterprise sector is recognized as key to reducing the burden on public expenditure and opening up private sector competition, the PRSP-PR merely sketches an agenda, without quantifying either the financial resources which could be liberated or those which would be required to compensate workers under the provisions of existing legislation.
} 
poverty reduction impact of public investment. While the new budget classification system has enabled poverty expenditures to be "tagged" for easier tracking, this is not the case for externally financed expenditures, in part because of different donor disbursement systems. The staffs support the PER recommendation that a donor assistance tracking system, similar to the one developed for Sierra Leone, be introduced. It would complement ongoing measures to improve governance of expenditure at the local level.

\section{B. Promoting Access to Basic Services}

13. The staffs generally concur with the PRSP-PR that the government has given continued priority to the social sectors, increasing government expenditures in spite of the difficult macroeconomic and budgetary situation. While the report indicates substantial progress in health and education, the staffs believe that further progress could be achieved through more efficient public services, improved effectiveness of spending in education, health and rural development, and better accountability for these expenditures.

14. Education. The staffs consider that the report gives insufficient attention to two urgent issues highlighted by the PER: the low percentage of non-salary recurrent budgetary resources reaching the primary school level and weaknesses in the recruitment, management and remuneration of teachers, including contract teachers. With regard to the first issue, the PER identified specific capacity-building measures and controls to be implemented at the sub regional level, for example, training of inspectors and school principals in simple accounting and the creation of community watchdog groups to participate in school budget formulation and in the supervision of budget execution. The generalization of local funding was originally planned for 2004 . The staffs consider that the report would have benefited from some discussion of the corrective measures being implemented. Regarding the second issue, the PER found that the recruitment of teachers, while growing rapidly, lacked adequate personnel management controls. It also found that almost thirty percent of the salary budget could not be linked to teacher personnel files, nor could the placement of teachers be verified. Also, recent significant increases in the pay of contract teachers is at odds with the policy of increasing access to schooling through the provision of teachers at a lower cost than teachers with civil service status. The staffs consider that the absence of adequate controls in these areas risks jeopardizing the attainment of the MDGs. The progress report could have indicated what measures have been undertaken or are planned to remedy these problems.

\section{The staffs also recommend that the next PRSP-PR place more emphasis on} the monitoring of indicators related to quality and access. The number of books per student by grade level is a good proxy for quality, as are teacher qualifications and experience, and the percentage of teachers who receive in-service training per year. Useful access indicators are the proportion of primary schools offering a full six-year course and the proportion of sixth grade students entering lower secondary school. The PER notes the wide discrepancies for this last indicator between regions. The staffs note that while the PRSP-PR does give some attention to access, it is silent on educational 
outcomes. It is important to learn whether children are attaining targeted standards of achievement in reading, writing and arithmetic, and whether the pedagogical methods are cost-effective. Achieving goals in participation and achievement is also critically dependent on teacher training. An accelerated approach to the pre-service training of primary school teachers was implemented in 2001. Since this approach is now fully operational, an assessment of its effectiveness seems important. Finally, achieving program goals in secondary education is tied to improvements in internal efficiency, yet the PER found that a high percentage of students in sixth grade were repeating that year and that there was a low rate of promotion to the first grade of lower secondary school, with wide variation in results between regions and between urban and rural schools. The staffs recommend that the next PRSP-PR give more attention to the issue of low internal efficiency.

\section{Health. The staffs consider that the PRSP-PR would have benefited from} more in-depth treatment of the issues identified by the PER and of the measures proposed to address them. Guinea's health outcomes are among the worst in the world, and public financing of the sector remains low at US\$3 per capita equivalent. In the pilot regions selected for the decentralization of expenditures, only 30 percent of the allocated non-salary budget reached the grassroots level and then only late in the budget year. Families are obliged to shoulder most of the operating costs and often cannot afford to access services. This issue could be explored further by a PSIA. The local resource problem is compounded by major and unexplained inequalities in the allocation of the health budget between regions, by the high levels of financing for tertiary care and administrative services, and by the concentration of health staff in the capital. This last factor leads to access ratios which vary from one midwife per 455 population in the capital to almost one per 176,000 in the most remote areas. As recommended by the last JSA, the staffs suggest that urgent attention be given to updating the sector strategy, defining new program targets, with projection budget requirements within the MTEF. Finally, the low availability of caregivers in outlying prefectures - as opposed to the Conakry Region - suggests that a new plan for the deployment and remuneration of personnel should be developed.

17. The staffs consider that the report would have benefited from an assessment of strategies which might address the issues of maternal health and HIV/AIDS, which are singled out in the PRSP-PR as important public health preoccupations. For example, women's knowledge could be improved through literacy programs or rural radio. The prevalence rate for HIV/AIDS cited by the report is for 2001. An updating of this figure together with progress indicators relative to measures to ensure a clean blood supply, reduce opportunistic infections and to assist AIDS orphans would have strengthened the report. The staffs note that the last assessment questioned whether program targets were technically and financially feasible and raised the specific concern of whether measures were in place, with adequate financing, to assist the growing number of AIDS orphans. The report would have been strengthened by discussion of the measures taken to address these issues. 
18. Rural Development. The staffs consider that the progress report would have benefited from an integrated assessment of the key indicators for rural poverty reduction, presenting a clearer picture of changes in rural life, including measures relative to the adoption of new farming practices and crop varieties, access to markets; access to primary schooling, basic health care and to clean water, as well as outreach to rural women, notably in terms of agricultural extension (women account for 80 percent of food crop production). Rural dwellers represent 80 percent of the population and 60 percent of the poor, with rural women the most affected. At the same time, reduction of poverty through growth will depend on the modernization and diversification of agriculture at the level of the small family farm as well at the plantation level. Government strategy reflects these concerns and one third of public investment and substantial HIPC funds are channeled into the sector. The staffs note that results are less clear, in part because the expenditure tracking exercise has not yet been completed for the sector. In the light of the poor results in education and health, the staffs consider it essential that this exercise be completed as soon as possible together with service delivery surveys, notably with regard to the impact of the agricultural research and extension services which are crucial to modernization and diversification. Finally, the sustainability of Guinea's road network and of rural works are essential for the development of the rural economy. Given the historically poor maintenance of Guinea's roads network, the staffs consider it important to ensure that the recurrent budget is adequate for the maintenance of the road network which has been largely rebuilt over the last decade. The sustainability of new rural works highlighted by the PRSP-PR presents a similar challenge.

\section{Strengthening Capacity and Promoting Governance}

19. Capacity Building. The staffs suggest that priority be given to strengthening the management of decentralized expenditures for core services. Lack of capacity to implement decentralization was recognized as a risk by the last JSA. It is also clear that the management of the civil service must be revitalized if delivery of basic services is to improve. The staffs recommend that special attention be given to planning career paths and incentives for field managers at the regional and prefecture levels. The staffs consider that getting the IDA-financed capacity-building project back on track will be an important factor in addressing this issue.

20. Governance. The staffs consider that the report would have benefited significantly from a discussion of the results of the anticorruption survey conducted in 2003 that identifies not only the levels of satisfaction with government departments, but also highlights specific corrupt practices. The results have implications for revenues, for growth through private sector development and for the quality of public services. The staffs recommend that the results be disseminated and broadly discussed. Other anticorruption agenda items still outstanding are the evaluation of sanctions already imposed; strengthening the prosecution of cases; the introduction of clearances for elected public officials, together with more stringent controls on their spending; and the independent audit of public contracts. A Country Procurement Assessment Report is also awaited. Finally, the staffs note that the proposed new institutional arrangements for the 
anticorruption campaign raise concerns for both its independence and efficacy. Results should be carefully monitored in the coming months.

\section{Participation in the PRSP Process}

21. The last JSA of July 2002 commended Guinea's efforts since 1998 to develop a strong participatory process, consulting stakeholders widely on the country assistance strategy and on poverty reduction through focus groups, regional workshops on strategy and through surveys. The staffs note the further progress achieved by the organization of regional workshops to discuss and validate regional poverty strategies. There is more to be done, however, in articulating the regional strategies with the national strategy and in making sure that they are reflected in the budgets of the priority sectors. The staffs consider that the next PRSP-PR could be strengthened by an assessment of the measures designed to deepen the consultative process, to improve the reporting of results and to increase community level participation in oversight.

\section{CONCLUSION}

\section{The staffs consider that the progress report reflects both the achievements} and shortcomings of the PRS. However, measures to improve performance and to alleviate the constraints to the strategy could be substantially reinforced. In the upcoming period of revision of the country's strategy, and in subsequent progress reports, the staffs consider that attention should be given to five main issues that are key to poverty reduction.

- Improved macroeconomic management. The dramatic slowdown in economic growth in 2003 urgently calls for sound macroeconomic policies and the pursuit of an ambitious agenda of structural reforms if poverty reduction is to be achieved. Further, it has shown the need to clearly assess the downside risks to the strategy, and plan corresponding mechanisms to limit their impact on poverty. Finally, the updated medium-term macroeconomic framework should include a revised debt-sustainability outlook with steps to normalize relationships with creditors.

- Sources of growth. The report could provide a more in-depth analysis of the constraints and the factors that promote economic growth, with a focus on improving economic diversification and productivity.

- $\quad$ Better public spending. In the promotion of access to basic services, the good progress already noted could be significantly enhanced by improving the effectiveness of public spending. The recommendations of the PER should be integrated fully in the strategy, building on the May 2004 workshop supported by the World Bank and other development partners. 
- Capacity building and governance. Better monitoring of decentralized expenditures for core services should be a priority in the PRS. Further, the anticorruption agenda should be pursued, as any setback would be very detrimental to the overall poverty reduction strategy. The conclusions of the anticorruption survey conduction in 2003 should be fully exploited.

- Strengthened analysis and monitoring of poverty. To better monitor the PRS, the household survey would need to be completed as soon as possible, and the authorities should draw on the available information, from the CWIQ, the PER, and the anticorruption survey. Fine-tuning the tracking of public expenditure is also important to ensure that poverty reduction efforts positively affect the poor.

23. The staffs discussed their conclusions with the authorities during the 2004 IMF Article IV consultations. The authorities were in broad agreement with the thrust of the comments and would incorporate them in the next progress report. The authorities also stressed that Guinea did not receive external budgetary assistance in the first two years of implementation of its PRS, severely limiting its ability to implement poverty reduction policies. They also noted that the lack of recent poverty indicators in the PRSP-PR is due to the fact that the results of the household survey were not available when the document was finalized, and that they will be fully reflected in the next progress report, providing a more in-depth analysis of poverty. The participatory process is moving forward with the organization of regional workshops and the articulation of the regional strategies with the national strategy. Although the progress report has been distributed to donors and made widely available, the staffs encouraged the authorities to proactively ensure wide dissemination of the progress report to stakeholders to inform them about the implementation of the PRS. ${ }^{4}$

24. In sum, notwithstanding worthwhile efforts, progress in the implementation of the strategy over the past two years has been constrained by a combination of policy slippages and exogenous shocks. Nevertheless, in light of the authorities' recent commitments to improve policies and advance reforms, the staffs of the Bank and Fund consider that the country's efforts toward implementation of the strategy provide sufficient evidence of its continuing commitment to poverty reduction, and therefore the strategy continues to provide a credible framework for Bank and Fund concessional assistance. The staffs recommend that the respective Executive Directors of the World Bank and the IMF reach the same conclusion.

\footnotetext{
${ }^{4}$ Several civil society organizations noted the limitations on dissemination imposed by the
} low level of literacy amongst the poor and lack of information in the main local languages. 